Original article

\title{
Exploring midwifery students' experiences \& perceptions of preceptorship project
}

\author{
Tahere Yaghoubi $^{1}$, Zeinab Hamzehgardeshi',*, Marjan Ahmad-Shirvani ${ }^{3}$, Mojtaba Vais-moradi ${ }^{4}$
}

(Received: 1 July 2014; Accepted 17 Aug 2014)

\begin{abstract}
Background and Purpose: Special attention has been paid to instructor and preceptor in nursing and midwifery education. This study aims to explore the experiences and Perceptions of midwifery students about implementing Preceptorship Program in delivery setting.

Methods: The current study is a qualitative research. The focus groups and in-depth interviews were used as data collection tools. Targetful sampling was employed to choose 10 midwifery students from Mazandaran University of Medical Sciences in order for them to participate in two discussion groups and in-depth interviews. The content analysis method was used for data analysis. Results: 10 categories, 5 themes and 238 codes were conducted. The themes were: the characteristics of a good preceptor, relationship, motivation and self-esteem, the expectations of a preceptor, and preceptorship experience.

Conclusion: The study showed that solving communication problems in educational environment, improving student-preceptor interaction, boosting motivation level and self-esteem among midwifery students, and coordinating procedures conduction are among the important principles of teaching and learning in clinical setting. The present study results can convey the essential knowledge to midwifery education planers on this aspect of educational process and benefit from the advantage of peer preceptors via the instructor's supervision.
\end{abstract}

Keywords: Preceptorship, Clinical skills, Delivery setting, Qualitative research

\section{Introduction}

As a branch of medicine, midwifery deals with maternal care, before, during and after delivery, and it is associated with all physiological, pathological, psychological and social factors, which influence the quality and quantity of the new generations (1). Clinical education and professional skills are considered to be the most important parts of nursing and midwifery education known as the focus of professional education $(2,3)$. Clinical education refers to preparing the students for consistent scientific data base, having skills of diagnosis, treatment, taking care of patients and acquiring different professional skills (4). Since the goal behind clinical education is providing the students with opportunities to match the theoretical information with practical realities, promoting its quality can lead to increasing the number of the students with clinical competence in different fields $(5,6)$. Since $50 \%$ of the nursing and midwifery educational programs are related

\footnotetext{
${ }^{1}$ Department of Management Nursing, Nasibeh Nursing \& Midwifery Faculty, Mazandran University of Medical Sciences, Sari, Iran. ${ }^{2, *}$ Corresponding author: Department of Midwifery and Reproductive Health, Nasibeh Nursing \& Midwifery Faculty, Mazandran University of Medical Sciences, Sari, Iran. Email: Hamzeh@razi.tums.ac.ir.

Traditional and Complementary Medicine Research Centre, Mazandaran University of Medical Sciences, Sari, Islamic Republic of Iran. ${ }^{3}$ Department of Midwifery, Nasibeh Nursing \& Midwifery Faculty, Mazandran University of Medical Sciences, Sari, Iran. ${ }^{4}$ Department of Medical Surgical Nursing, Nursing \& Midwifery Faculty, Tehran University of Medical Sciences, Tehran, Iran.
} 
to the clinical courses, the clinical environment is the necessary source in preparing the students for their professional role $(4,7)$. For the first time, Mentorship and Preceptorship was used commonly in the 1970s and 1980s, as a way to improve professional performance in the U.S (8), and it was used by the private sectors in the U.K for management training in late 1980s. In 1990, mentorship and preceptorship became known in society, and now it plays a significant role in the constant development of nursing profession and teaching (9).

Special attention has been paid to instructor and preceptor in nursing and midwifery education. The presence of a skilled and professional person with the students removes their anxiety, confusion, improves their professional skills, promotes their active learning, creates an appropriate learning environment for fresh students and the responsibility and self-confidence for senior students and increases interaction among the students $(3,10,11)$. Preceptorship has been consistently acknowledged in the literature as a strategy to maximize the benefits of clinical education in terms of knowledge, practice, confidence, and professional skills (12).

Preceptors are an invaluable and dramatic resource to prepare the students for their professional roles (13). There are many definitions for Mentorship and Preceptorship. According to the definition proposed by the National Nursing and Midwifery Board of England (2001), the term mentor and preceptor is used to define a nurse and midwife playing the role of a learning facilitator, supportive and assessor of the students in the clinical environment $(14,15)$. In some studies, it has been mentioned as a supervisor, an instructor, a trained person or a senior student. In recent years, being a preceptor has drawn special attention in nursing and midwifery, and practicing it is suggested as a method in order to prevent anxiety, confusion, to promote active learning, to create appropriate learning environment, self-confidence, to increase interaction among the students and to prevent the nursing students' desertion or disappointment $(16,17)$. A research aiming to explore the nursing staff's experience from preceptionship project indicates what might reduce stress level for the preceptor and increase job satisfaction and nurse's retention (18).

Midwifery students need a preceptor in every stage of the clinical training. According to Midwifery and Nursing Association (2008), the results of implementing preceptorship include providing an effective business communication, facilitating learning, assessment and responsibility, learning assessment, creating a learning environment and evidence-based clinical education and guidance (19). To achieve these results, a preceptor should provide continuous support to facilitate learning and give effective feedback. A mentor and preceptor is the key factor behind the students' clinical competence improvement in the clinical environment (20).

Research has denoted that a mentor and preceptor is one of the most important factors affecting learning and improving the students' self-confidence (21-24). In addition, the preceptor-student supportive relationship enhances the clinical environment and learning quality (20). In fact, the value of a good mentor and preceptor cannot be measured (25). In Queensland University of Technology, a Registered Nurse (RN) is used as a mentor and preceptor. These nurses participate in the project voluntarily. At the end of the second year of nursing bachelor course, the students take part in the project as a Mentee. In this model, mentorship and preceptorship is defined as the participation, cooperation, and friendly \& promoting relations, it also involves professional education and leadership. In other studies, senior students have been used as preceptors $(10,16,26$, and 27). A number of researchers have examined the effects of mentorship and preceptorship project on stressing the clinical environment factors for the nursing students $(10,16)$. An Iranian study divided 70 sophomore nursing students into two groups of 35 (control and case) in a semi-experimental survey. The researchers have reported that implementing preceptorship project has positive effects on reducing the stress of the clinical environment factors for sophomore nursing students (16). 
The literature review suggested that most of the studies were quantitative conducted among the nursing students $(21,26-31)$. According to the researcher's studies, no study has been conducted on implementing preceptorship project and exploring Iranian midwifery students' experiences about this project implementation in maternity hospital. Based on the researcher's experience, as a clinical service provider and clinical instructor in maternity environment, the challenge has always been evident that students face with stress and anxiety about the clinical environment on their arrival; and the presence of a skilled and compassionate instructor helps them to overcome their stress and it facilitates learning. Since a preceptor has a crucial role in the students' learning and the improvement of maternity facilitates learning, and due to different nature of midwifery clinic from the other sectors, the researchers decided to implement the preceptorship project in maternity for the midwifery students and then to survey the students' experiences and perceptions of the project through a qualitative research.

\section{Materials and Methods}

Design: The present study is a qualitative research of content analysis type. Participants have been chosen based on targetful sampling and took part in deep individual interview and focus group discussion (FGD). The major question of this study is: "What is the understanding and perception of midwifery students about the implementation of preceptorship in labour room?" A qualitative approach has been used to answer this question. The specific characteristic of the qualitative research is its exploratory nature, and its goal is to describe, explain and understand the phenomenon. The approach chosen for this study allows the participants to express their experiences about preceptorship, use their own words, without being exposed to predetermined responses of the quantitative research. On the other hand, not being able to generalize the other cultures' studies to our culture, conducting a qualitative research becomes more necessary in order to make the understanding and experiences of the midwifery students clear in consistent with the facilities and characteristics of our clinical environment. In this approach, content analysis is an appropriate method for the texts subjective interpretation through the process of systematic coding classification and the available patterns or themes allocation (32).

Setting and Participants: It is worth to explain that 42 senior midwifery students accompanied 42 freshman midwifery students 3 days weekly for three weeks, fulltime $\&$ before the study. The required explanations about the research objectives and processes were given to the students and instructors. During the project implementation, the senior students taught the fresh ones via the indirect supervision of the instructor; the instructor entered the teaching session when necessary and guided the training directly. At the end of the period and during the present study, the group discussion was held by the enthusiastic and highly informed students.

Data Collection: The focus group discussion was used in present study other than the deep individual interview in order to explore the participants' experiences of preceptorship project. The semistructural interview and open-ended questions were applied in this study. The focus group discussion (FGD) is an interview in a semi-organized group under the leadership of a specific individual in an informal situation to increase the information quality and quantity by the group activity. Since the interview is held with a group, rather than the individuals, it is more flexible and thought-provoking and helps to remember the information and appropriately to enrich the information. Unlike the other methods, it is not based on an individual's point of view, rather on the result and sum of a group's thinking.

The following questions were employed as the interviews guideline:

"Please express your feeling about your expectation about this preceptorship project?"

"Which factors did you take as the facilitators and barriers? Please elaborate on how each factor affects your physical activity." 
Students were asked to express their experiences about the project at the beginning of the discussion with regard to the ethical standards of qualitative research and according to the principles of maintaining anonymity, information confidentiality, the right to quit the study at anytime and finally acquiring an informed consent form from the participants. The general questions with open and descriptive responses were also designed as semistructured interview guide, and the students' responses led the process. All of the conversations were recorded and transcribed, and then the content analysis was used (33). The time allocated for each group discussion was 90 minutes and interviews continued until the data saturation was achieved.

Profound and exploratory questions such as 'why', 'how' and 'give explanation' were also given to the groups based on their responses in order to perceive the depth of their experience.

The following methods have been applied in order to increase the data consistency similar to the quantitative studies' validity and reliability: Member check has been used to ensure the accuracy and strength of the research data. Members of the study reviewed the derived interviews, codes and classifications in order to investigate the coding process's accuracy and determine if they have achieved the same codes. The researcher's creditability was used in the second stage. In order to review the manuscripts of the participants, the relationship with the participants increased, and to ensure the accuracy of the data, the interviews were held in more meetings. Peer debriefing was used in the third stage, that is, to use the peers' additional comments \& notes and the data results were given to the colleagues and experts to confirm the results $(33,34)$.

Ethical approval was obtained from the Ethics Committee of Mazandran Medical Sciences University. Analysis: The data analysis was done with the purpose to get the themes. Based on content analysis definition, it is a method of objective, systematic and quantitative obvious content communication description. However, over time it changed to include the interpretation of the hidden content communication (34).
In this study, the conventional qualitative content analysis was used in which the categories have been derived from the data and not from the primary theory (35). Also, the MAXQDA10 software (a computer software simplifying qualitative data analysis) was applied for the data management (36). The individuals' expressions about their life experiences and histories were qualitatively dissected into small parts and were descriptively analyzed (37). Content analysis method is defined as a method for objective systematic description of manifest communication content; furthermore, this method includes explaining the latent communications content (38). In the present study, both of the contents (manifest and latent) have been evaluated. Generally, the qualitative content analysis in this study was performed as the following:

1- Initially, the vocal files of the interviews were transcribed; then, by precisely reading the transcriptions, the authors tried to understand the external and internal components of these experiences.

2- $\quad$ By reviewing the transcriptions, the narratives were identified and the categories were formed after doing the primary coding.

3- Synchronically, analytical memos were written in order to determine the primary relationship between the intentions obtained from the participants' expressions.

4- $\quad$ By the interviews progression, the relationship between the intentions was specified in order to find out the main models and meanings in the interviews.

5- And finally, considering the content analysis, constant comparison method was employed in the study implementation. This method based goals are to compare different individuals' opinions and experiments about the phenomenon, to specify why the experiments and opinions are different or similar, and to determine how they are related to each other (39).

\section{Results}

Five main themes were achieved from the interviews and focus group discussions, each of them with several categories. The main themes included: the 
characteristics of a good preceptor, communication, motivation and confidence, the expectations of a preceptor and the experiences of preceptorship. These basic themes and categories were explained using some examples given by the study participants.

Theme 1: Characteristics of a good preceptor: Most of the participants mentioned availability, empowerment, and self-confidence, well mannered and evidencebased working as the obvious traits of a decent preceptor. In this study, the students believed that a good preceptor is a very effective factor in facilitating learning, boosting confidence and lowering anxiety.

Availability: "A good preceptor is a person who is always accessible" (A bachelor student).

Practical \& Theoretical Empowerment: "A good preceptor is a person who is well informed and experienced in practical courses" (A bachelor student).

High Self-esteem: "In addition to being theoretically and practically experienced, a good preceptor must have high self-esteem and should be able to make proper decisions in critical situations" (A senior student).

Well Mannered \& Encouraging: Most of the students asserted that a decent preceptor is the one who encourages students to learn through asking appropriate questions besides being well-mannered and supportive in clinical situations.

"A person, who thoroughly explains the clinical and theoretical points, teaches us useful skills at proper times and supports us in stressful situations." (A bachelor student).

According to the students, it seems that being sure of the practical and scientific abilities of the preceptor is of the most important factors:

"A good preceptor is a person who encourages us to study more and perform our clinical courses better, gives us the freedom to take delivery cases, but has control over our job for the patients' convenience. She has practical and theoretical skills and is not bothered by our questions." (A senior student)

Evidence-based Practice: Most of the midwifery students believed that a good preceptor does not work based on her previous and old knowledge, rather tries to review the new research cases, updates her information, conducts the clinical works based on the evidences and teaches the students.

"A good preceptor reviews the new articles and is upto-date even clinically." (A senior student)

Theme 2: Communications: Another given code is related to humanistic and emotional communication of the students collectively and with the preceptor. Promoting the humanistic relationships in professional and intimate situations is stated as one of the merits of a preceptor. According to the students, this communication must be respectful, and the scientific information of the senior students is effective in fresh students' learning.

Communication-related skills, especially an individual's ability to communicate, seem to be very critical in creating the balance in professional and friendly relationships:

"Since my preceptor was a student like me, I felt comfortable. Although I kept a distance from the preceptor as my senior, we were like friends." (A bachelor student)

"Since my preceptor was also a student and we were female and homogeneous, we talked a lot in our free time. She was more experienced than me and guided me; we still have a close relationship." (A bachelor student)

Some of the students suggested that some preceptors tended to make less communication due to the weakness of knowledge and skills.

"My preceptor did not have a good interaction with me; she always seemed to resist against me. She was theoretically weak and did not talk to me because she was afraid that if I asked a question and she could not reply; but I knew human being is not a computer to remember everything immediately, she could search and answer me the next session." (A bachelor student).

Theme 3: Motivation \& Self-esteem: According to the students, being unfamiliar with the maternity hospital was the most important stressful factor, and the students mentioned the presence of the preceptor as stress-reducing factor. Research has shown that a preceptor is an effective factor in raising the students' 
self-esteem. The current study students also stated that the presence of the fresh students in the project helped them to raise their confidence and their learning motivation.

"The project reduced freshmen's stress and increased our self-esteem." (A senior student)

Some of the participants expected their preceptor to have the capability to transfer the information and meanings.

Theme 4: Expectations of Preceptor: "My preceptor could be a very good midwife, she had a very good relationship with her patients and her clinical work was excellent, but she was not a good preceptor, she could not express herself properly." (A bachelor student)

Some of the students mentioned the contradictory expectations of the preceptors and believed that they should be coordinated with each other and the students:

"Some preceptors expect us to do whatever they want, which is not our duty, and even if it is, the other preceptors do not ask their students, why there is no coordination?" (A bachelor student)

Theme 5: Preceptorship Experience

Gradual Achievement of Independence: Most of the students stated that they extremely depended on their preceptors at the beginning of the project; but they gradually achieved the required experience and selfconfidence to act independently.

"At first, I was very dependent on my preceptor but she gradually trusted me and I started to work independently, under her supervision." (A bachelor student)

Hope for Professional Success: They believed that the experience of working with a preceptor leads to their future professional success. One of the bachelor students stated:

"I'd like to have different preceptors and benefit from the experience of all of them in order to be better able to decide about my future method of work and learn many things from different preceptors."

Feeling Happy \& Lucky: Students who had the experience of a good and intimate preceptor felt so lucky and happy. According to a fresh student:

"I was really lucky to have a good and kind preceptor.
She was one of the cleverest and confident students of the university, I learned a lot from her.

Management, Equipment and Physical Space Factors: Since management, personnel and physical environment of training has a crucial role in learning, and the communication style, skills and personnel's cooperation are effective in creating a positive learning environment, students consider these factors to influence the improvement of their learning process; they mentioned proper communication of treatment team members with the trainees, the behaviour of the preceptor with the instructor and personnel and having enough equipment as the effective factors boosting their learning. Following it is the experience of a senior student of the project:

"The maternity hospital where the project was implemented was an appropriate place because other students were not like residents and we could work easily. Students fill the forms in our hospital to give us a responsibility. In order to have better cooperation, it is better for the manager and staff of the hospital to be informed of the project".

Evaluation: Due to group nature of preceptorship project, the participants in the study pointed out final the training evaluation as participatory and believed that it enhances learning process and performance of the students, the instructor and even the personnel.

"The senior students' comments were important to evaluate fresh students but it would have been better if they asked increase the responsibility of fresh students and accountability of the seniors. Students 'evaluation must be participatory since the project was a group work." (A senior student)"

Shifting conditions: All of the students agreed with full and night shifts in the project. They expressed that long sifts with a short break increased their training quality. They believed that they could learn labour control and delivery in these shifts.

"In my opinion, the project must not be implemented in one shift since there is less chance of delivery; Long shifts were appropriate for the project." (A bachelor student) 


\section{Discussion}

The results of the study implied that midwifery students who participated in the study named lowering anxiety, boosting motivation and self-esteem and improving communication as the merits of the project. The study participants suggested the lack of coordination between the theoretical and clinical education was as the project stressful factor. Similar results were obtained in other studies $(10,16$, and 40$)$.

Similar to the results of other studies, the majority of the students in the current study had positive experience about the project, which facilitates their learning (16, 26, and 40). Asefzadeh et al. (2000) studied 45 fresh medical students with 9 junior students (preceptors) in Qazvin Medical University. The study was run for a year. The students were evaluated at the end of the year. All of the students were satisfied with the project. Scott et al. (2005) implemented studentstudent preceptorship project for nursing students, they communicated via email and phone. In the first year, all of the students had positive experience about the project and believed it leads to professional and the leadership skills promotion. In addition, the researchers maintained that the project prevents disappointment in the students.

In the present study, there was consensus about the characteristics of a good preceptor. According to the students, an efficient preceptor is a person who is supportive and has enough scientific and practical information, expressive skills and high self-esteem. Most of the participants had good experience about the preceptorship project. As the students said, a decent preceptor must encourage students to midwifery and clinical tasks and give them appropriate feedback to facilitate learning.

The findings of this study are consistent with the other studies implying the value of a good preceptor is not measureable. As a result, a preceptor is effective in creating trust and confidence in the students to perform clinical tasks independently (25). The current study findings suggest that the students' self-confidence is the result of their experience and their preceptor's view.
A good preceptor motivates her trainees and facilitates learning; these findings are compatible with the results of the previous studies (20).

In the present study, the students had various experiences of a good preceptor. One of the criteria was availability of the preceptor in different situations. They also noticed their negative experience as being afraid of asking questions since the preceptor got angry and could not reply to the questions on the spot. A study indicated that the negative experience of asking questions was related to the feeling of ignorance and stupidity (41). None of the students in this study mentioned these feelings and words.

The current study has been conducted in the clinical maternity hospital environment for midwifery students. The senior students have been used as preceptors since guiding in labour and delivery process is necessary. The interview with the preceptor and learners has been held in order to explain the students' experience of consulting project in the maternity hospital. The study findings are as the improvement of communication problems in educational environment, increased interaction between the students and instructors and the enhancement of motivation and confidence in the midwifery student as the basic principles of teaching and learning in the clinical setting. Since using lowcost methods to promote learning quality is essential for the managers, it is suggested that the administrators of midwifery education focus more on this aspect of education, and boost learning process quality by employing senior students under the supervision of the instructor.

The study limitation was not being able to employ all of the senior students as the preceptors. We hope that in next year project all of the fresh students be employed as preceptors. Senior (preceptors) and fresh students would be assigned and the preceptors would guide the fresh students through email, phone or their presence in university until the start of training. At the end of the year, their performance would be evaluated by the cooperation of the students, instructors, lecturers and university officials. 


\section{Conclusion}

The study finding revealed that the removal of communication problems in educational environment, the improvement of student-preceptor interaction, the enhancement of motivation level and self-esteem among midwifery students, and coordination in conducting the procedures are among the critical principles of teaching and learning in clinical setting.

\section{Conflict of Interests}

The authors declare that they had no competing interests.

\section{Author's Contributions}

All five authors contributed to the development of the study ideas and design. Z.Hamze-gardeshi wrote the first draft of the manuscript reviewed by the other authors. The final version of the manuscript was critically reviewed by Z.Hamze-gardeshi. All authors read and approved the final manuscript.

\section{Acknowledgments}

We are grateful to all of the midwifery students and their instructors who participated in the project for their sincere cooperation. The present study was conducted as a research project and supported by a grant (No.8910-01-89150) from the Research Council of Mazandran Medical Sciences University.

\section{References}

1. Myers Ciecko JA. Evolution and current status of direct entry midwifery education, regulation, and practice in the united states, with examples from Washington state. J Nurse Midwifery. 1999; 44(4): 384-93.

2. Hadizadeh F, Firoozi M, Razavi S. Nursing and midwifery students perspective on clinical education in Gonabad university of medical sciences. Iranian Journal of Medical Education. 2005; 5(1): 70-78 (persian).

3. Schrubbe KF. Mentorship: a critical component for professional growth and academic success. Journal of dental education. 2004; 68(3): 324-328.
4. Salehi,Sh, Rahimi M, Ali Abedi H, Bahrami M. Students experience with the hidden curriculum in faculty of nursing and midwifery of Isfahan University of Medical Sciences. Pejouhesh in Medicine. 2003; 27(3): 217-223 (persian).

5. Hassan Zahraei R, Atash Sokhan G, Salehi SH,Ehsanpour S, Hasanzadeh A. Comparing the factors related to the effective clinical teaching from faculty members' and students' points of view. Iranian Journal of Medical Education. 2008; 7(2): 249-256.

6. Lowenstein AJ, Bradshaw MJ. Fuszard's innovative teaching strategies in nursing.3rd ed. United States: Jones \& Bartlett; 2004.

7. McAllister L, Lincolin M, McLeod S. An adult learning framework for clinical education. Facilitating learning in clinical settings: London: Stanley Thorns Publishers; 1997.

8. Clutterbuck D. Everyone needs a mentor: Fostering talent in your organisation.4th ed. London: CIPD Publishing; 2004.

9. Girot EA. Assessment of graduates and diplomats in practice in the UK-Are we measuring the same level of competence? J Clin Nurs . 2000; 9(3): 330-337.

10. Sprengel AD, Job L. Reducing student anxiety by using clinical peer mentoring with beginning nursing students. Nurse Educ. 2004; 29(6): 246-250.

11. Oliver C, Aggleton P. Mentoring for professional development in health promotion: a review of issues raised by recent research. Health Education. 2002; 102(1): 30-38.

12. Happell B. A model of preceptorship in nursing: reflecting the complex functions of the role. Nurs Educ Perspect. 2009; 30(6): 372-376.

13. Lofmark A, Thorkildsen K, Raholm MB, Natvig GK. Nursing students' satisfaction with supervision by preceptors and teachers during clinical practice. Nurse Educ Pract. 2012; 12(3): 164-169.

14. Rigotti NA, Lee JE, Wechsler H. US college students' use of tobacco products: results of a national survey. JAMA. 2000; 284(6): 699-705.

15. Miller C,Tomlinson A,Jones M. English National Board for Nursing Midwifery and Health Visiting Preparation of Mentors and Teachers. Standars for approval of higher education insitutions and programs. 
ENB 997/998. London; 1994.

16. Yaghoubian M, Salmeh F, Yaghoubi T. Effect of mentorship program on the stressors in the nursing students during their clinical practice. J Mazandaran Univ Med Sci. 2008; 18(66): 42-50.

17. Butler MP, Cassidy I, Quillinan B, Fahy A, Bradshaw C, Tuohy D, et al. Competency assessment methods "Tool and processes: A survey of nurse preceptors in Ireland. N Nurse Educ Pract. 2011; 11(5): 298-303.

18. Omansky GL. Staff nurses' experiences as preceptors and mentors: an integrative review. J Nurs Manag. 2010; 18(6): 697-703

19. Han M, Kim K, Ryu S, Kang M, Park J. Associations between smoking and alcohol drinking and suicidal behavior in Korean adolescents: Korea Youth Behavioral Risk Factor Surveillance, 2006. Prev Med. 2009; 49(2-3): 248-252.

20. Licqurish S, Seibold C. Bachelor of Midwifery students' experiences of achieving competencies: the role of the midwife preceptor. Midwifery. 2008; 24(4): 480-489.

21. Gray M, Smith L. The qualities of an effective mentor from the student nurse's perspective: findings from a longitudinal qualitative study. J Adv Nurs. 2000; 32(6): 1542-1549.

22. Randle J. The effect of a 3 year pre registration training course on students' self esteem. J Clin Nurs. 2001; 10(2): 293-300.

23. Begley CM. Great fleas have little fleas': Irish student midwives' views of the hierarchy in midwifery. J Adv Nurs. 2002; 38(3): 310-317.

24. Papp I, Markkanen M,Bonsdorff MV. Clinical environment as a learning environment: student nurses' perceptions concerning clinical learning experiences. Nurse Educ Today. 2003; 23(4): 262-268.

25. Miles S. Make or break: the importance of good mentorship. Br J Midwifery. 2008; 16(11): 704-7011.

26. Scott ES. Peer-to-peer mentoring: teaching collegiality. Nurse Educ. 2005; 30(2): 52-56.

27. Asefzadeh S, Javadi HR, Sharifi M. Mentorship at qazvin medical school: a pilot study in Iran. Journal of Medical Education . 2009; 4(2): 85-88.

28. Tepper BJ . Consequences of abusive supervision.
ACAD MANAGE J. 2000; 43(2): 178-190.

29. Eby LT, McManus SE. The protégé's role in negative mentoring experiences. J Vocat Behav. 2004; 65(2): $255-275$

30. Eby LT Butts MM, Durley J, Ragins BR. Are bad experiences stronger than good ones in mentoring relationships? Evidence from the protégé and mentor perspective. J Vocat Behav. 2010; 77(1): 81-92.

31. Rusbult CE. Commitment and satisfaction in romantic associations: a test of the investment model. J Exp Soc Psycho. 1980; 16(2): 172-186.

32. Pope C, Mays N. Qualitative research: reaching the parts other methods cannot reach: an introduction to qualitative methods in health and health services research. BMJ. 1995; 311(6996): 42-45.

33. Pope C, Mays N, Ziebland S. Qualitative methods in health research. Qualitative research in health care 2000; 2: 1-10.

34. Ulin PR, Robinson ET. Qualitative methods in public health: a field guide for applied research. New Jersey: Jossey-Bass ; 2004.

35. Holdford D. Content analysis methods for conducting research in social and administrative pharmacy. Res Social Adm Pharm. 2008; 4(2): 173-181.

36. Kuckartz AM, Kuckartz U. Qualitative text analysis with MAXQDA. Fundacin Centro de Estudios Andaluces; 2002.

37. Holloway I. Qualitative research in health care. Milton Keynes(UK): Open University Press; 2005.

38. Graneheim UH, Lundman B. Qualitative content analysis in nursing research: concepts, procedures and measures to achieve trustworthiness. Nurse Educ Today. 2004; 24(2): 105-112.

39. Given LM. The Sage encyclopaedia of qualitative research methods.California: Sage Publications; 2008.

40. Taghavi Larijani T, Ramzani F, Khatouni AR, Monjamed Z. Comparison Of The Sources Of Stress Among The Senior Nursing And Midwifery Students Of Tehran Medical Sciences Universities. J HAYAT. 2007; 13(2): 61-70.

41. Gillen P, Sinclair M, Kernohan WG, Begley C. Student midwives' experience of bullying. Evidence Based Midwifery. 2009; 7(2): 46-53. 